\title{
Control Strategy to Maximize the Power Capability of PV Three-Phase Inverters During Voltage Sags
}

\author{
Jorge Luis Sosa, Miguel Castilla, Jaume Miret, Member, IEEE, José Matas, and Y. A. Al-Turki
}

\begin{abstract}
Under voltage sags, grid-tied photovoltaic inverters should remain connected to the grid according to low-voltage ride-through requirements. During such perturbations, it is interesting to exploit completely the distributed power provisions to contribute to the stability and reliability of the grid. In this sense, this paper proposes a low-voltage ride-through control strategy that maximizes the inverter power capability by injecting the maximum-rated current during the sag. To achieve this objective, two possible active power situations have been considered, i.e., high- and low-power production scenarios. In the first case, if the source is unable to deliver the whole generated power to the grid, the controller applies active power curtailment to guarantee that the maximum rated current is not surpassed. In the second case, the maximum allowed current is not reached, thus, the control strategy determined the amount of reactive power that can be injected up to reach it. The control objective can be fulfilled by means of a flexible current injection strategy that combines a proper balance between positive- and negative-current sequences, which limits the invert output current to the maximum rated value and avoid active po oscillations. Selected experimental and simulation results ported in order to validate the effectiveness of the proposed itrol strategy.
\end{abstract}

Index Terms-Distributed PV generation, lowthrough, maximum-rated current, reactive power in cion, vol sag.

$\mathbf{I}_{\mathrm{s}}^{\mathrm{N}}$ $\mathrm{N}$ recent years, environmental significantly the number of grid-c ation (DG) systems [1], [2]. However, th of DG systems can introduce a negative stability and reliability of the grid infrastruc der grid fault conditions. In this sense, grid countries with high penetration level of DG ha procedure that they should follow under such situations.

Manuscript received February 16, 2015; revised May 19, 2015; accepted June 22, 2015. This work was supported in part by the Ministerio de Economía y Competitividad of Spain and FEDER founds under Grant ENE2012-37667C02-02, the Programa Iberoamericano de Ciencia y Tecnología para el Desarrollo under Grant 713RT0475, and the Deanship of Scientific Research, King Abdulaziz University, Jeddah, under Grant 24-135-35-HiCi. Recommended for publication by Associate Editor L. Chang

J. L. Sosa is with the Scientific Instrumentation Laboratory, Universidad de los Andes, Mérida 5101, Venezuela (e-mail: jorgesosa5@gmail.com).

M. Castilla, J. Miret, and J. Matas are with the Department of Electronic Engineering, Technical University of Catalonia, Barcelona 08034, Spain (e-mail: miquel.castilla@upc.edu; jaume.miret@upc.edu; jose.matas@ upc.edu).

Y. A. Al-Turki is with the Renewable Energy Research Group, King Abdulaziz University, Jeddah 22254, Saudi Arabia (e-mail: yaturki@yahoo.com).

Color versions of one or more of the figures in this paper are available online at http://ieeexplore.ieee.org.

Digital Object Identifier 10.1109/TPEL.2015.2451674
In compliance with these requirements, DG sources must remain connected to the grid during voltage sags, following a predefined time/sag-depth profile before disconnection, which is known as low-voltage ride-through (LVRT). Additionally, wind GCs require the injection of the reactive power to support the grid voltage and to reduce the possibility of voltage collapse [3]-[5]. Consequently, it is expected that the continuously increasing number of grid-connected DG will promote new requiremen in GCs. Upcoming GCs could demand also reactive power ction from distributed PV systems to fully exploit the react power provisions [4]-[6].

der these quirements, different LVRT strategies have propos onhance the performance of DG during voltage sags . Most of corted works are based on symmetric sequen since thej se increases the fl ibility and leads to achieve p cular atrol objectives su as the mitigation of acti and ro ower oscillations, vo pert, and peak As presented in [7] and [8], by means onspacs strategies it is possibl obtain different power quality levd the point of com coupling (PCC) in terp active nd $r$ cive power oscillations. Ho ver, avol act vower ations results more favorable the DG per mance, since thoractive power oscillations are $r$ cted as ri le in the dclink voltage and could cause sudden d, nnect of the voltage source inverter (VSI) if th araxin de-link voltage is surpassed/under pass

In voltage supportstr gies, the p rity is to deliver only the reactive power dur the It can attributed to the major impact that the ra five culares on the PCC voltages when amak gri considerea. Depending on the type of sag, diffe jo pu strategies can be applied [9] and [10]. In a ref hee-cu $t$ generation algorithm that provides xible volta support introduced. An improvement of [9] ough liy ed to symmetric sags was presented in [10], where tho SC Atages can be restored if the DG system supplies enou active current. The authors in [9] present a voltage control the can be used under any type of sag.

To avol connection of the DG source due to overcurrent, the injected pase currents must be safely controlled at any time. In this regard, different strategies have been proposed. The control method presented in [11] ensures minimum peak values in the grid-injected currents when the whole generated power is delivered to the grid. However, current harmonic distortion was increased to meet the control objectives and the resulting minimum values always exceeded the VSI-rated current. In [12] and [13], the injection strategies avoid over current tripping, but the maximum output current was only related to the 
maximum reactive power delivered by the VSI under unbalanced grid conditions. As a drawback, the source is unable to deliver the active power production. Moreover, the active and reactive power present oscillations at twice the grid frequency. The approach presented in [14] is based on the virtual flux estimation method. In this paper, different active and reactive power injection strategies have been proposed, however, not all of them ensure maximum current limitation. In [15] and [16], more flexible controllers have been proposed. These controllers provide different LVRT services by injecting active and reactive power by means of positive and negative sequences while maintaining the injected current safely controlled to a predefined maximum value. However, the control algorithms are complex when comparing with previous schemes.

This paper proposes a compact LVRT control strategy that guarantees the complete use of the power capabilities of the distributed PV system under voltage sags. The proposal comprises a set of reference currents that provides flexible positive and negative active and reactive power injection characteristics that can be tuned to fulfill two objectives during voltages sags: first, to inject maximum rated current independently of the sag profile and, second, to avoid active power oscillations. Both objectives will be always accomplished, although the achie ment of first objective could be affected by the amount of generated power. In this concern, two main possible sc may be considered, i.e., high- and low-power produc narios. In the first case, the injection of the maxim can be achieved delivering only active power, whi pliance with present PV GCs. Moreover, if the to deliver the whole generated power, the co plies active power curtailment to avoid sy rated current and avoid disconnection du second case, a combination of active and injected to reach the inverter maximy the PV system can provide support Although actual PV GCs do not requ tion, this functionality could contribute to distributed resources in the near future.

Some of the reviewed control strategies ovide peakcurrent limitation and flexible operation under oltage sags. However, none of the presented strategies so far is able to determine the reference currents that optimize the VSI power capabilities in an easy manner with simple and compact reference expressions as presented here. Therefore, control simplicity is one of the remarkable contributions of this paper.

This paper is organized as follows. Section II describes the grid-connected DG system, analyzes the PCC voltages and inverter currents under a voltage sag event, and describes the GC requirements that must be applied under this situation. Section III exposes the conditions that give rise to control objectives and proposes a strategy to achieve it. Section IV develops the theoretical basis of the control proposal. Section V corroborates the expected features of the proposed controller by means of selected simulation and experimental results. Also, a discussion of the outstanding characteristics of the proposed strategy is presented, including a comparison with reported peak current

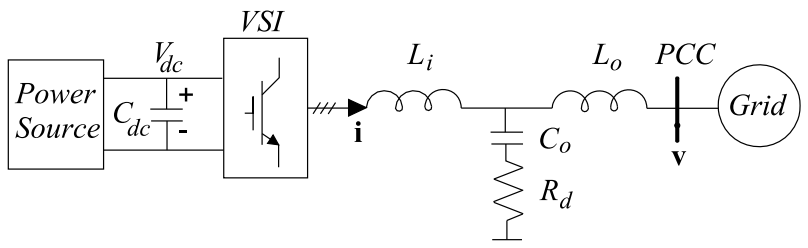

Fig. 1. Diagram of a grid-connected DG.

limitation controllers. Section VI presents the conclusions of 144 this paper.

\section{GRID-CONNECTED INVERTERS UNDER VOLTAGE SAGS}

This section deals with the description and characterization of the grid-connected VSI under voltage sags. Also, the basic $\mathrm{GC}$ requirements during these disturbances are described.

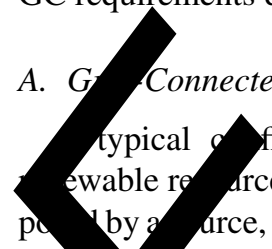

Three-Phase Inverter

iguration of grid-connected DG based on ces is shown in Fig. 1 [2]. Basically, it is comarce, a larg dc-link capacitor employed for decouplin surce and converter, and a three-phase three-wire VSI co cted to PCC. The invert ses an LCL filter to reduce th ou quency commutatio armonics [17], [18]. amping resistors series with capacitors in order to $p$ resonance effects [17) Vhe voltage in the dc link is regula to extract the maximy power from the source usip ink voltage contr which provides the gen wed ac pow erence t should be injected into the rid. This c roller has been 162 ely studied in the literature, a this paper [18], [19].

\section{B. Voltage Sag Chara}

A voltage sag is a prt-time re ction of the rms voltage magnitudes in on or grid pl ses which can be caused by different types of line se to ground short-circuit, phase round shore corrcuit), overload, or power-up of 1 22]. During voltage sags, the VSI suffers a seve erturb n that can compromise its functionality d reliabil For this son, the voltage and current vectors the PCC ust be properly characterized in order to deal with

1. stantaneous PCC phase voltages during voltage sags can bo scribed as the addition of positive-, negative-, and zero-sym ric sequences. By means of Clarke transformation, the instanta ous PCC phase voltages can be expressed in the stationary reference frame (SRF) as

$$
v_{\alpha}=v_{\alpha}^{+}+v_{\alpha}^{-}=V^{+} \cos \left(\omega t+\delta^{+}\right)+V^{-} \cos \left(\omega t+\delta^{-}\right)
$$

$v_{\beta}=v_{\beta}^{+}+v_{\beta}^{-}=V^{+} \sin \left(\omega t+\delta^{+}\right)-V^{-} \sin \left(\omega t+\delta^{-}\right)$

where $v_{\alpha}$ and $v_{\beta}$ are the SRF components of the measured 180 voltage at PCC, $v_{\alpha}^{+}, v_{\beta}^{+}$, and $v_{\alpha}^{-}, v_{\beta}^{-}$are the SRF positive- and 181 negative-voltage sequences, respectively, $V^{+}$and $V^{-}$are the se- 182 quences amplitudes, $\omega$ is the grid angular frequency, and $\delta^{+} 183$ 
and $\delta^{-}$are the initial phase angles of positive- and negativesequences, respectively. Note that the zero sequence is not considered here, since it is not present in three-wire systems [8].

There are different types of voltage sags, which can be characterized by the sequences amplitudes, $V^{+}, V^{-}$, and by the sequence phase angle $\delta$. The magnitudes of these parameters can be determined using the SRF theory [21], [22], as

$$
\begin{aligned}
V^{+} & =\sqrt{\left(v_{\alpha}^{+}\right)^{2}+\left(v_{\beta}^{+}\right)^{2}} \\
V^{-} & =\sqrt{\left(v_{\alpha}^{-}\right)^{2}+\left(v_{\beta}^{-}\right)^{2}} \\
\delta=\delta^{+}-\delta^{-} & =\cos ^{-1}\left(\frac{v_{\alpha}^{+} v_{\alpha}^{-}-v_{\beta}^{+} v_{\beta}^{-}}{V^{+} V^{-}}\right) .
\end{aligned}
$$

\section{Requirements for DG systems Under Voltage Sags}

Under normal grid conditions, VSI delivers all the generated active power into the grid by controlling the amount of the injected current. During voltage sags, complementary services can be required by the GCs to increase the grid quality and reliability. Wind GCs require LVRT capabilities and support the grid with some amount of reactive current injection. This amount varies depending on the regulations of each country; in extrey cases, it can arrive to $100 \%$. Furthermore, depending on th profile, GCs also require active and reactive power injeg simultaneously feed and support the grid [3]-[5]. Pre GCs for PV systems only require the injection of the active However, reactive power injection could be den ded in near future to fully exploit the reactive pow provisions distributed PV systems [4], [6].

\section{PROBlem Formul}

The purpose of this section is to have set the foundation of the propose and the objectives that can be reached. $\mathrm{f}$ algorithm that leads to its practical implem

\section{A. Power Injection During Voltage Sags}

According to the power theory [23], [24], the instantaneous active and reactive powers injected to the grid by a three-phase VSI depends on the injected currents and the voltage vectors (i, v) at the PCC. Thus, the instantaneous power can be defined as

$$
\begin{aligned}
& p=\frac{3}{2}\left(v_{\alpha} i_{\alpha}+v_{\beta} i_{\beta}\right) \\
& q=\frac{3}{2}\left(v_{\beta} i_{\alpha}-v_{\alpha} i_{\beta}\right) .
\end{aligned}
$$

Additionally, the VSI current references can be decomposed in active and reactive components as

$$
\begin{aligned}
& i_{\alpha}^{*}=i_{\alpha}^{*}(p)+i_{\alpha}^{*}(q) \\
& i_{\beta}^{*}=i_{\beta}^{*}(p)+i_{\beta}^{*}(q) .
\end{aligned}
$$

In compliance with present GCs, the PV systems must only inject the active power into the grid. To achieve this requirement, the following set of reference currents in the SRF can be used

$$
\begin{aligned}
& i_{\alpha}^{*}(p)=\frac{2}{3} \frac{v_{\alpha}^{+}}{\left(V^{+}\right)^{2}} P^{*} \\
& i_{\beta}^{*}(p)=\frac{2}{3} \frac{v_{\beta}^{+}}{\left(V^{+}\right)^{2}} P^{*} .
\end{aligned}
$$

In this scheme, the reference currents follow the positive- 222 sequence voltage. Thus, the resulting currents are balanced and 223 free of harmonics. However, during unbalanced voltage sags, 224 this strategy introduces an oscillation in the injected active 225 power at twice the grid frequency which affects negatively the 226 dc-link voltage and may cause dc overvoltage problems [25]. 227

During the sag, the amplitude of the positive sequence $V^{+} 228$ will be reduced. Consequently, according to (10) and (11), the 229 injected currents will increase to maintain the same amount of 230 injected pawer previous to the sag. However, this conventional 231 respons ay lead to tripping or damage of the converter be- 232 cause reference currents might surpass the inverter maximum 233 rate arrent. In is situation, the source is unable to inject the 234 ve genera power. Thus, safety mechanisms must be acti- 235 vat to ren e the excess of active power production that may 236 prod. Ank overy age and overcurrent disconnection. A 237 method yoid the roblems is the act power curtailment. 238 It compris e r of the active pow ccording to specific 239 re ements neans of auxiliary sys ouch as dc-link 240 age limiter units or by detuning the $\mathrm{M}$ operation point 241 26], [27]. 242 On the ner hand, if the calculated pance ca nts do not 243 xceed maximum rated current ang ag, inverter 244 W apability is not completel xploited. this situation, 245 Ne power injection could be $\alpha$ sidered to the maxi- 246 mum rated current and maximize th verter p er capability. 247 To solve the aforementip ans (i.e., 248 to avoid active power allatio, o avord inverter tripping 249 due to over current, an to inject reactive power when is 250 possible), a new cyarer control str gy that maximizes the 251 inverter power cap Mlitid propos below. 252

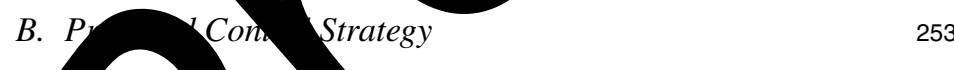
Aexible re ence cun s are needed. Thus, based on [9], a 255 $\mathrm{X}$ set of rence currents is defined as 256 $i_{\alpha}^{*}(p)=\frac{2}{3} \frac{k_{p}^{+} v_{\alpha}^{+}+k_{p}^{-} v_{\alpha}^{-}}{k_{p}^{+}\left(V^{+}\right)^{2}+k_{p}^{-}\left(V^{-}\right)^{2}} P^{*}$ $\rho)=\frac{2}{3} \frac{k_{p}^{+} v_{\beta}^{+}+k_{p}^{-} v_{\beta}^{-}}{k_{p}^{+}\left(V^{+}\right)^{2}+k_{p}^{-}\left(V^{-}\right)^{2}} P^{*}$

$$
\begin{aligned}
& i_{\alpha}^{*}(q)=\frac{2}{3} \frac{k_{q}^{+} v_{\beta}^{+}+k_{q}^{-} v_{\beta}^{-}}{k_{q}^{+}\left(V^{+}\right)^{2}+k_{q}^{-}\left(V^{-}\right)^{2}} Q^{*} \\
& i_{\beta}^{*}(q)=-\frac{2}{3} \frac{k_{q}^{+} v_{\alpha}^{+}+k_{q}^{-} v_{\alpha}^{-}}{k_{q}^{+}\left(V^{+}\right)^{2}+k_{q}^{-}\left(V^{-}\right)^{2}} Q^{*}
\end{aligned}
$$

where $k_{p}^{+}, k_{p}^{-}, k_{q}^{+}$, and $k_{q}^{-}$are the control parameters to bal- 257 ance appropriately the positive and negative sequences. These 258 


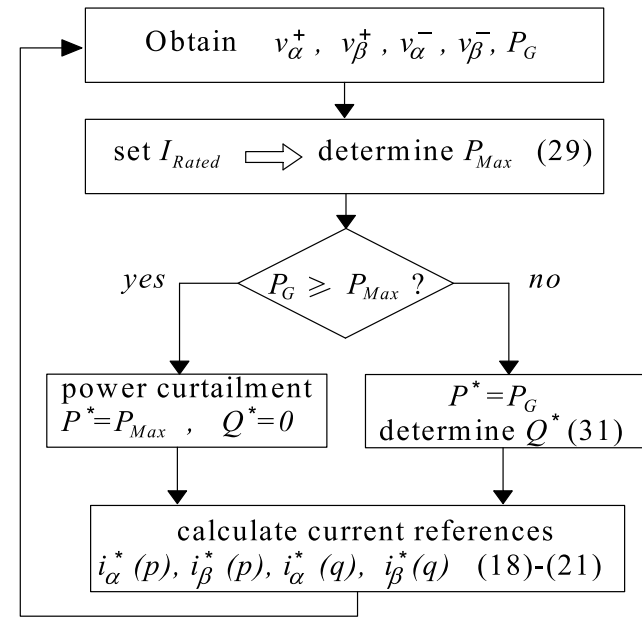

Fig. 2. Flux diagram of the proposed control strategy.

parameters can take any values in the range 0 to 1 , which give rise to multiple injection strategies. For instance, the simple injection strategy represented by (10) and (11) can be implemented with the proposed reference currents by selecting the control parameter as $k_{p}^{+}=k_{q}^{+}=1$ and $k_{q}^{-}=k_{p}^{-}=Q^{*}=0$

Thus, based on (12)-(15), a control strategy that detern adequately the power references $\left(P^{*}, Q^{*}\right)$ to fulfill the $\mathrm{p}$ control objectives is presented. The operation of the control strategy can be described by the algorithm Fig. 2. In this figure, the generated active power is obtained from the dc-link voltage regulat and negative-voltage sequences are obtained extractor which let to determine the sag [29]. Next, the maximum allowable act; the VSI can provide $\left(I_{\text {Rated }}\right)$ and $Q=0$. compared with $P_{G}$ to determinate If $P_{\mathrm{G}}$ is higher than $P_{\mathrm{Ma}}$, the strateg ment to avoid exceeding $I_{\text {Rated }}$. Conseq the active power reference has to be set as reactive power reference is maintained as $Q$ hand, if $P_{G}$ is lower than $P_{\mathrm{Max}}$, then, the inver rated current is not surpassed and, therefore, som the reactive power can be injected up to reach $I_{\text {Rated }}$. In this case, the reactive power reference $Q^{*}$ is calculated considering $I_{\text {Rated }}$ and the generated power $P_{G}$. Finally, the reference currents are computed with the corresponding values of active and reactive power references. The selection of the control parameter and the development of the mathematical expressions that allows the online determination of $P_{\mathrm{Max}}$ and $Q^{*}$ will be shown in Section IV.

\section{Theoretical Approach to the Control Strategy}

The purpose of this section is to develop the mathematical expressions that support the statements of the proposed control strategy. Furthermore, the effects that the proposed reference currents and control parameters cause in the instantaneous active and reactive power are presented.

\section{A. Determining Maximum Injected Current}

To fulfill the control objective of avoiding active power oscil- 297 lations, the control parameters are selected as

$$
\begin{aligned}
& k_{p}^{-}=-k_{p}^{+} \\
& k_{q}^{+}=k_{q}^{-} .
\end{aligned}
$$

The achievement of this objective will be validated theoret- 299 ically in Section IV-C and experimentally in Section V. Addi- 300 tionally, thanks to (16) and (17), the proposed reference currents 301 (12)-(15) become simplified and normalized as follows:

\section{$i_{\beta}^{*}(q$}

$$
\begin{aligned}
& i_{\alpha}^{*}(p)=\frac{2}{3} \frac{v_{\alpha}^{+}-v_{\alpha}^{-}}{\left(V^{+}\right)^{2}-\left(V^{-}\right)^{2}} P^{*} \\
& i_{\beta}^{*}(p)=\frac{2}{3} \frac{v_{\beta}^{+}-v_{\beta}^{-}}{\left(V^{+}\right)^{2}-\left(V^{-}\right)^{2}} P^{*}
\end{aligned}
$$
302
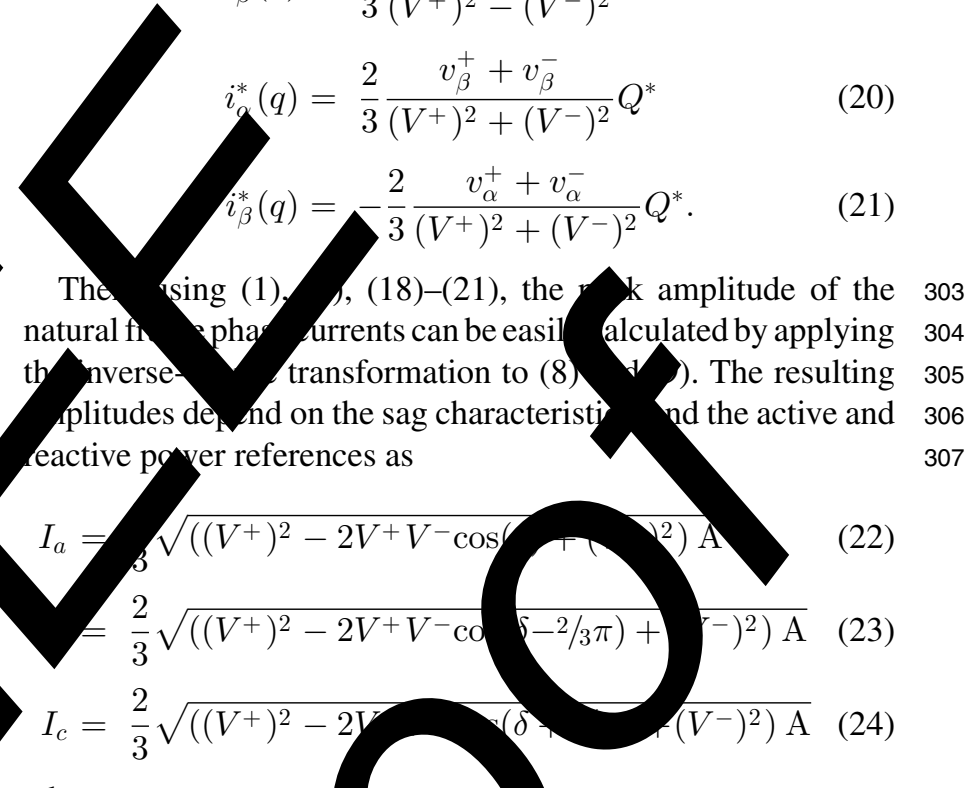

where

$$
\left.\mathrm{A}=\left(\frac{V^{+} \boldsymbol{Q}}{\left(V^{-}\right)}\right)^{2}+Q_{\left.V^{+}\right)^{2}+\left(V^{-}\right)^{2}}\right)^{2} .
$$

T. measuring the sag characteristics $\left(V^{+}, V,-\delta\right)$ and knowing the $y$ and reactive power references, the maximum phase current an tude can be easily determined as

$$
I_{\mathrm{Max}}=\frac{2}{3} \sqrt{\left(\left(V^{+}\right)^{2}-2 V^{+} V^{-} \cos _{\min }+\left(V^{-}\right)^{2}\right) \mathrm{A}}
$$

where $I_{\mathrm{Max}}$ is the maximum output current that the VSI will 315 provide.

To avoid inverter damage or disconnection by the overcurrent, 317 $I_{\mathrm{Max}}$ must be limited to the VSI-maximum-rated current by 318 means of the following condition:

$$
I_{\text {Max }} \leq I_{\text {Rated }}
$$




\section{B. Determining Maximum Active and Reactive Power}

The maximum power that the VSI can deliver during the sag must be determined considering (28). Also, variations in the generated power due to different environmental conditions must be considered. Therefore, high- and low-power production scenarios can be studied during the occurrence of grid faults.

Scenario 1(High power generation): In this case, $I_{\mathrm{R} \text { ated }}$ could be surpassed due to the generated power $P_{\mathrm{G}}$. In this situation, the source is unable to inject the whole generated power, and active power curtailment is necessary. Then, the maximum active power that can be injected into the grid during the sag can be determined by using $I_{\mathrm{Max}}=I_{\text {Rated }}, P^{*}=P_{\mathrm{Max}}$, and $Q^{*}=0$ in (27), and solving the resulting expression for $P_{\mathrm{Max}}$

$$
P_{\text {Max }}=\frac{3}{2} \frac{I_{\text {Rated }}}{\sqrt{\mathrm{B}}}\left(\left(V^{+}\right)^{2}-\left(V^{-}\right)^{2}\right)
$$

where

$$
\mathrm{B}=\left(V^{+}\right)^{2}-2 V^{+} V^{-} \cos _{\min }+\left(V^{-}\right)^{2} .
$$

In this case, the active and reactive power references are $P^{*}=P_{\mathrm{Max}}$ and $Q^{*}=0$.

Scenario 2(Low power generation): In this case, the gener power $P_{G}$ is lower than $P_{\mathrm{Max}}$, and the inverter maximum current cannot be reached, then, some amount of the power can be injected to increase the VSI output curren maximum value in order to support the grid. Under this the reactive power reference can be determined by $I_{\text {Rated }}$ and $P^{*}=P_{G}$ in (27) and solving the res for $Q^{*}$

$$
Q^{*}=\sqrt{\frac{2.25 I_{\text {Rated }}^{2}}{\mathrm{~B}}-\left(\frac{P_{G}}{\left(V^{+}\right)^{2}-\left(V \mathbf{\mathbf { V } ^ { 2 }}\right.}\right)}
$$

In this case, the active power referen

$$
\text { It is worth mentioning that (29) and (3i }
$$

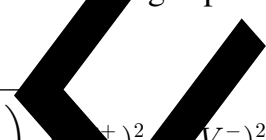
to its pact expressions that facilitate the applicat simplo $0 \mathrm{~m}$ control strategy. As far as author's knowledge pressions have not been reported previously in literature, thus, together with the flux diagram shown in the Fig. 2, these constitute the two main theoretical contributions of this paper.

\section{Determining Power Oscillations Components}

During voltage sag, the instantaneous active and reactive powers injected by the VSI can be decomposed in the following expressions:

$$
\begin{aligned}
& p=P^{+}+P^{-}+\tilde{P} \\
& q=Q^{+}+Q^{-}+\tilde{Q}
\end{aligned}
$$

where $P^{+}, Q^{+}, P^{-}, Q^{-}, \tilde{P}$, and $\tilde{Q}$ represents the positive and negative components and the oscillating terms of the active and reactive power, respectively.

By inserting (1)-(2) and (12)-(15) into (6) and (7), (32) and (33) can be developed as a function of $V^{+}, V^{-}, \delta$, and the

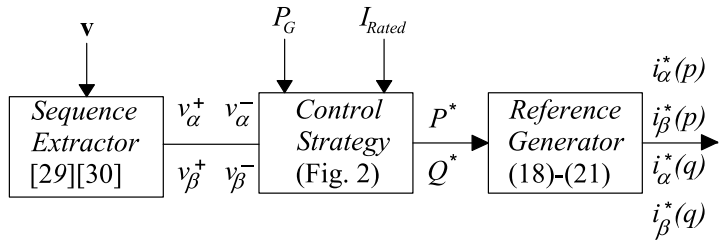

Fig. 3. Block diagram of the proposed control scheme.

control parameters as

$$
P^{+}=\frac{k_{p}^{+}\left(V^{+}\right)^{2}}{k_{p}^{+}\left(V^{+}\right)^{2}+k_{p}^{-}\left(V^{-}\right)^{2}} P^{*}
$$

$$
P^{-}=\frac{k_{p}^{-}\left(V^{-}\right)^{2}}{k_{p}^{+}\left(V^{+}\right)^{2}+k_{p}^{-}\left(V^{-}\right)^{2}} P^{*}
$$

Then, by replacing th 1 copo coltw parameters $\left(k_{p}^{-}=361\right.$ $-k_{p}^{+}$and $k_{q}^{+}=k_{q}^{-}$) in (4)-(39), resulting instantaneous 362 active and reactive pow can be wri $h$ as 363

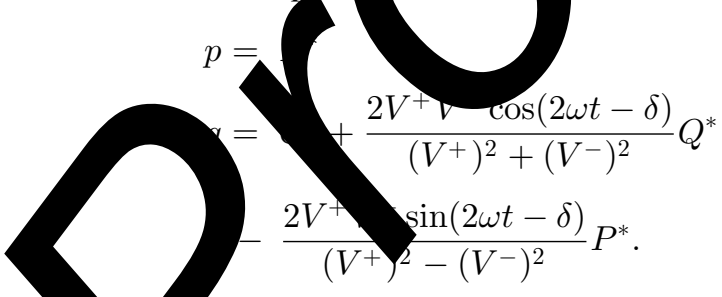
inject ctive power is removed completely, which brings ben- 365 efits to $1 \mathrm{c}$-link performance. On the other hand, the reactive 366 power has llations at twice the line frequency, but ensuring 367 a mean value $Q^{*}$.

\section{Proposed Control Scheme}

A simplified diagram of the control proposal is shown in 370 Fig. 3. The inputs of the controller are the measured phase 371 voltages $\mathbf{v}$ at the PCC, and the generated power $P_{G}$ provided by 372 the dc-link voltage controller. Voltage vector $\mathbf{v}$ is converted into 373 SRF values by means of Clarke transformation. Then, voltages 374 $v_{\alpha}$ and $v_{\beta}$ are decomposed into symmetric components using 375 


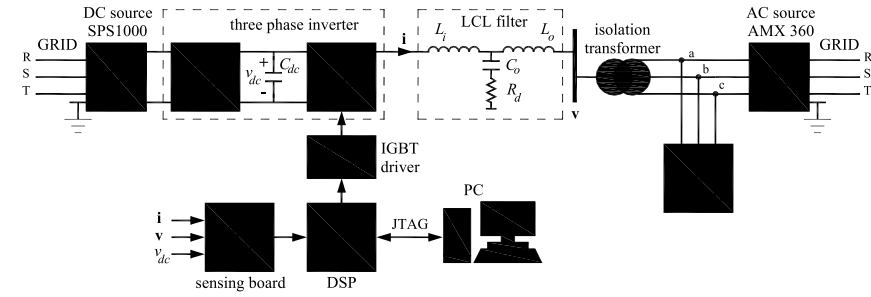

Fig. 4. Diagram of the experimental setup.

TABLE I

SYSTEM PARAMETERS

\begin{tabular}{lcc}
\hline \hline Nominal rated power (base power) & $S_{b}$ & $2.3 \mathrm{kVA}$ \\
\hline Generated active power & $P_{G}$ & 300,900, and $1300 \mathrm{~W}$ \\
Nominal grid voltage & $V_{g}$ & $110 \mathrm{Vrms}$ \\
Rated current amplitude & $I_{\mathrm{R} \text { ated }}$ & $10 \mathrm{~A}$ \\
Nominal grid frequency & $f_{o}$ & $60 \mathrm{~Hz}$ \\
DC-link voltage & $V_{\mathrm{dc}}$ & $350 \mathrm{~V}$ \\
DC-link capacitor & $C_{\mathrm{dc}}$ & $1.5 \mathrm{mF}$ \\
$L C L$ inverter-side inductances & $L_{i}$ & $5 \mathrm{mH}$ \\
$L C L$ filter capacitors & $C_{o}$ & $1.5 \mu \mathrm{F}$ \\
$L C L$ damping resistors & $R_{d}$ & $68 \Omega$ \\
$L C L$ output-side inductances & $L_{o}$ & $2 \mathrm{mH}$ \\
Sampling/Switching frequency & $f_{s}$ & $10 \mathrm{kHz}$ \\
\hline \hline
\end{tabular}

a sequence extractor. The core of the controller is th ontrol strategy block, whose operation has been described It uses the information provided by the sequenc the inputs, $P_{G}$ and $I_{\text {Rated }}$, to calculate the necessary to implement the proposed refere

\section{EXPERIMENTAL R}

Fig. 4 shows a diagram of the exp mental prototype rated at $2.3 \mathrm{kVA} \mathrm{wa}$ three-leg bridge, an $L C L$ power filter, former, and a local load. A TMS320F283
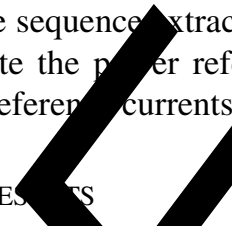
rimenta. ilt usir behavior is emulated using an AMREL-SPS 0 dc source. The utility grid is emulated by means of a progra nable threephase Pacific AMX-360 ac source connected to the PCC. The sequence extractor is implemented with generalized integrators [28], [29]. The current controller consists of proportionalresonant controllers [30]. Table I lists the parameter values for both the inverter and the controller.

Throughout this paper, two power production scenarios have been considered: high and low. However, an additional medium production scenario has been also included in this section, in order to highlight the flexible characteristic of the proposed control scheme. Then, three different power production tests have been considered to obtain experimental results: low-, medium-, and high-production scenarios.

A variable-profile voltage sag has been programmed in the ac source to evaluate the behavior of the system. The programmed sag in three different power production tests will follow the same sequential behavior. First, during $0.1 \mathrm{~s}$, the grid voltages are roughly balanced with the following rms voltages: 1.018,
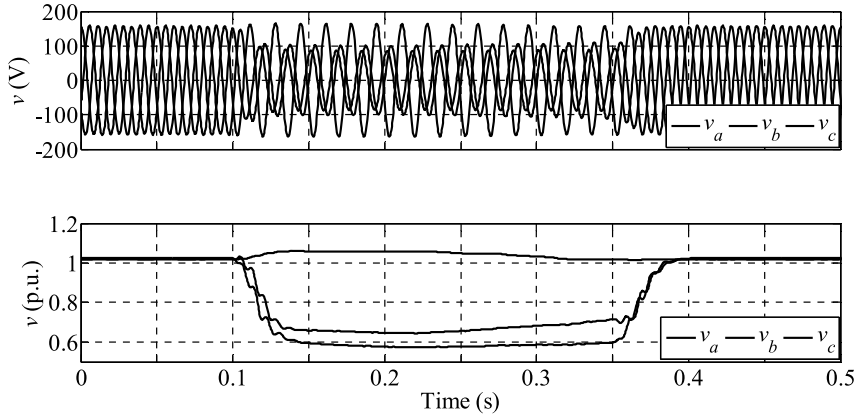

Fig. 5. Experimental PCC phase voltages during the sag (top), and its rms values (bottom)

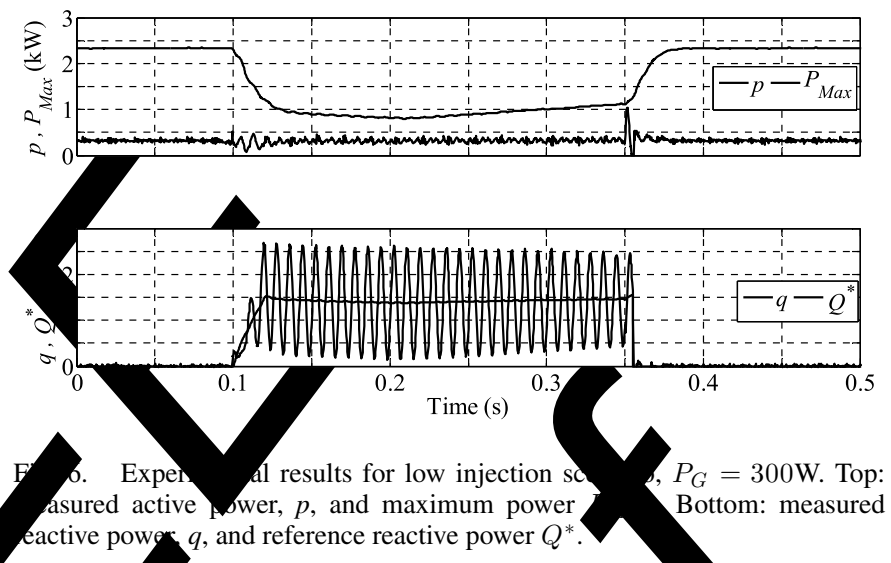

1.025 d 1.021 p.u. Then, at $t$ ases voltages drop well beld

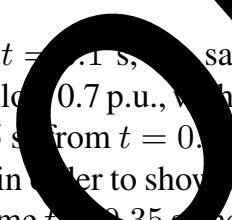
ears and 406 the control strategy. Finall ne $t \quad 25$ nag is cleared 410 and the dropped voltag begin retumro its presag values. 411 Fig. 5 shows the PCC e-to-neut phase voltages during the 412 $\begin{array}{ll}\text { sag and its rms per } 1 \text { ni alues. } & 413\end{array}$ A. Low Active a fer Injen lario 414 F instantaneous active and reactive power 415 ng the $t$ cons $\operatorname{ing} P_{G}=300 \mathrm{~W}$, i.e., a low-production 416 enario. $\mathrm{Tl}$ mean val of the active power is $300 \mathrm{~W}$ for the 417 ration of e test (see the line depicted in blue). In red line, 418 naxi $m$ active power $P_{\text {Max }}$ that could be injected without 419 sur $\mathrm{g} I_{\text {Rated }}$ is depicted in the figure. Then, when the sag 420 begin proposed current controller calculates on-line $P_{\mathrm{Max}} \quad 421$ for this ific fault. Observe that $P_{\text {Max }}$ is reduced from $2.3 \quad 422$ $\mathrm{kW}$ to a m hum value of $800 \mathrm{~W}$ during the sag. As it can be 423 seen, the power produced by the system never reaches $P_{\mathrm{Max}}, \quad 424$ thus $P^{*}=P_{G}$ during the entire test. Under this condition, the 425 inverter is able to provide some reactive power till the maximum- 426 rated current $I_{\text {Rated }}$ of the inverter is reached. The measured 427 mean value of the injected reactive power is almost $1.4 \mathrm{kVAr} \quad 428$ during the sag, clearly following its reference value $Q^{*}$. When 429 the sag takes place, the system becomes unbalanced and an 430 oscillation at twice the line frequency appears in the reactive 431 power. In the case of the active power, observe that thanks to 432 


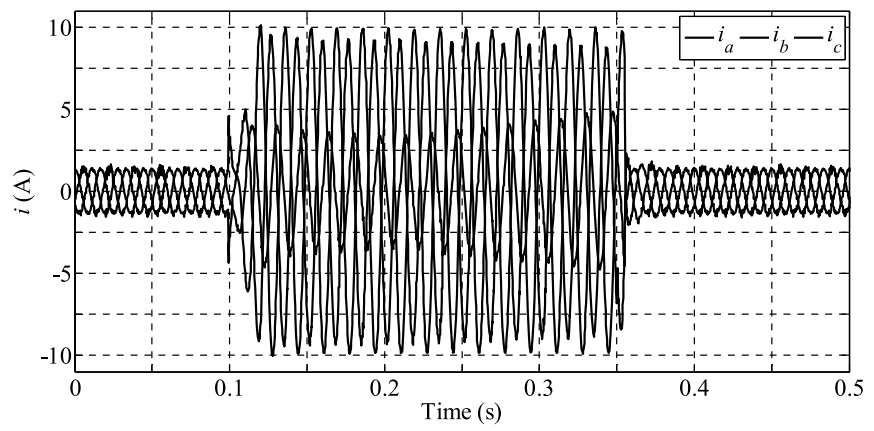

Fig. 7. Experimentally measured line currents for low injection scenario, $P_{G}=300 \mathrm{~W}$.

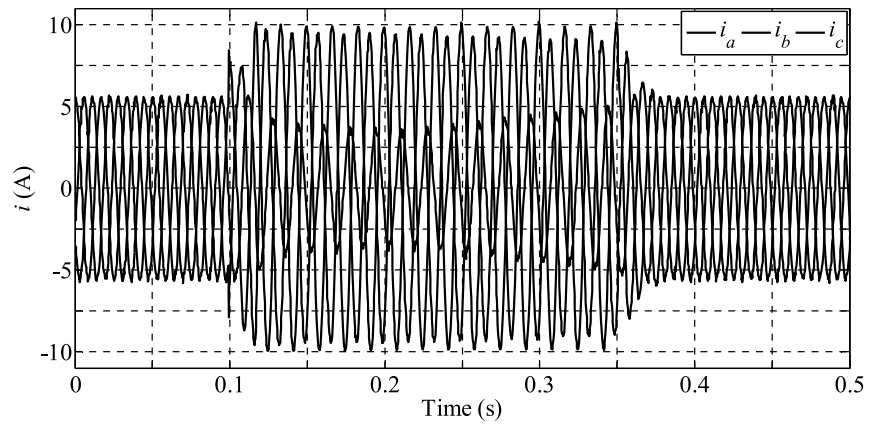

Fig. 9. Experimentally measured line currents for high injection scenario, $P_{G}=1300 \mathrm{~W}$.
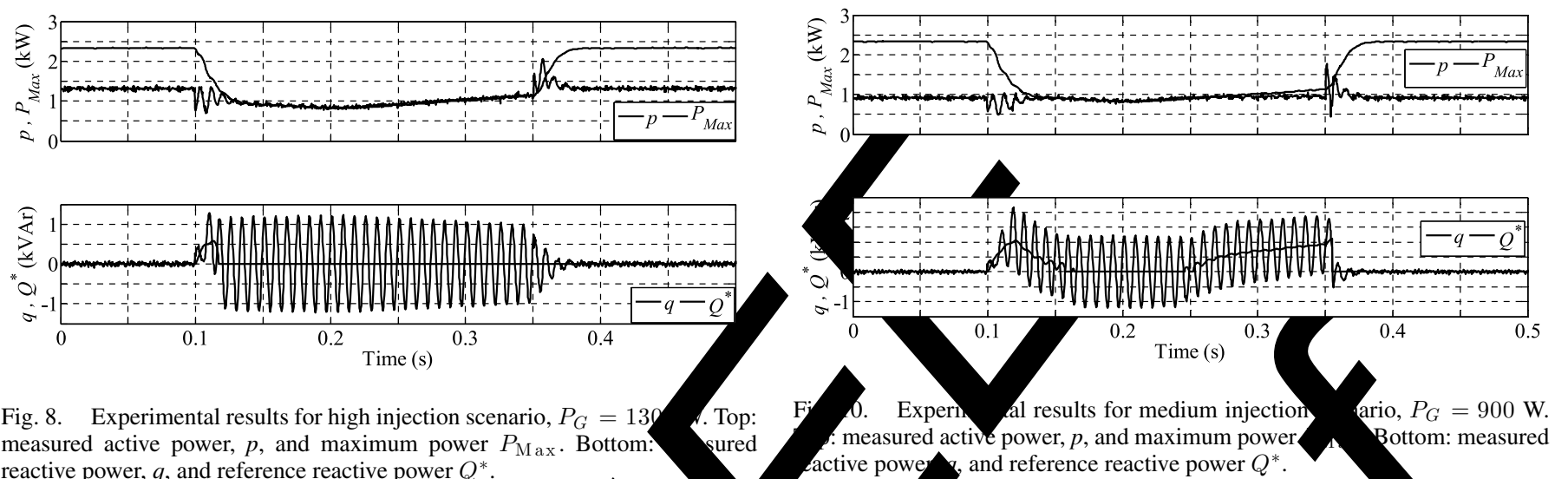

Fig. 8. Experimental results for high injection scenario, $P_{G}=130$. Top: measured active power, $p$, and maximum power $P_{\mathrm{Max}}$. Bottom reactive power, $q$, and reference reactive power $Q^{*}$.

the selection of the control parameters (16), have been avoided as desired.

Fig. 7 shows the injected currents durin of the sag appearance, the objective of inje allowed current is fulfilled in one phas Note of the other phase currents are chan the variable profile of the voltage sa maximum-rated current.

\section{B. High Active Power Injection Scenario}

Fig. 8 shows the instantaneous active and reactive powers during the fault considering $P_{G}=1300 \mathrm{~W}$, i.e., a highproduction scenario. The mean value of the injected active power is $1300 \mathrm{~W}$ before and after of the sag, $P^{*}=P_{G}$. On the other hand, as it can be observed, the maximum active power $P_{\mathrm{Max}}$ is surpassed by the produced power during the sag. Under this condition, the power production must be curtailed to avoid overcurrent and disconnection. During the sag, the active power reference is limited to $P_{\mathrm{Max}}$, i.e., $P^{*}=P_{\mathrm{Max}}$. Thus, in this test, no reactive power can be provided since the maximum output current of the inverter $I_{\text {Rated }}$ has been reached. It is important to note that the voltage sequences detector has a one grid-cycle settling-time response, which introduces a delay in the reactive power reference $Q^{*}$ calculation. This effect can be observed at the beginning of the sag, when the reactive power injection is not zero and reaches $500 \mathrm{VAr}$ during one grid cycle. However, after this small time interval, the reactive power referer reaches its expected valy $Q^{* *}=\operatorname{VAr} \gg$ mean Also, an oscillation in the active po at twice the 460 equency is observed, which oborates t prediction of 461 the previous analysis. Fig. 9 shows injected arrents during 462 the test. After $0.015 \mathrm{~s}$ of injecting the maximum owed ca $\mathrm{nt}$ is fulfilled. C. Medium Active wo njection S nario 465 Fig. 10 show insta 4 active and reactive power 466 during faul sidering $T_{G}=900 \mathrm{~W}$, i.e., a medium- 467 prof (10i nario mean value of the injected active power 468 $10 \mathrm{~W}$ bef and a the sag, $P^{*}=P_{G}$. A combination of 469 previous enarios ca e observed in Fig. 10, from the be- 470 ing of sag until $0.15 \mathrm{~s}$ and from $0.25 \mathrm{~s}$ to the end of 471 tho which the active power generated by the system is 472 beloh ax and some reactive power can be injected. Among 473 these th tervals, $P_{\mathrm{Max}}$ is surpassed and the power production 474 must be ch led $\left(P^{*}=P_{\mathrm{Max}}\right)$ to avoid overcurrents. Fig. 11475 shows the in weted currents during this test. This test reveals the 476 excellent dynamic properties of the proposed control strategy 477 which provide smooth transitions between the operation modes 478 (i.e., active power curtailment and reactive power injection). $\quad 479$

\section{Supporting Different Types of Voltages Sags}

A complete set of simulations has been carried out to further 481 demonstrate the effectiveness of the control proposal under any 482 type of voltage sag. The system with parameters described in 483 


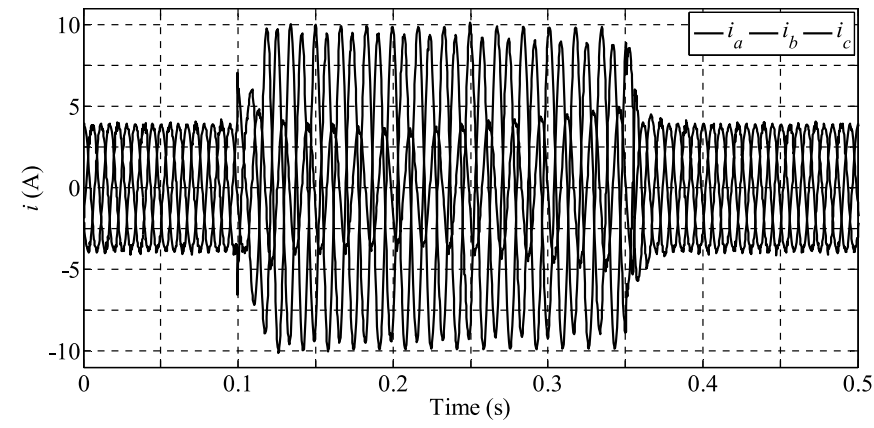

Fig. 11. Experimentally measured line currents for medium injection scenario, $P_{G}=900 \mathrm{~W}$.
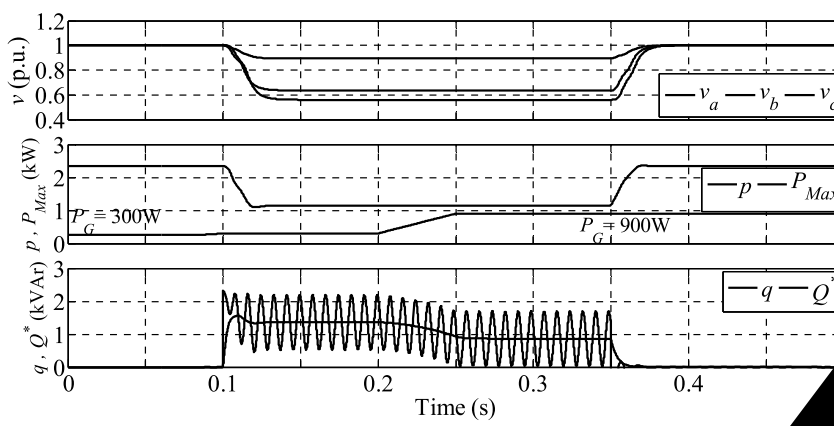

Fig. 12. Simulation waveforms for type-II sag $\left(V^{+}=0.68\right.$, $\delta=10^{\circ}$ ). Top: PCC rms phase voltages. Middle: generated active maximum power $P_{\mathrm{Max}}$. Bottom: measured reactive power, $q$, an reactive power $Q^{*}$.

rence during the sag, beginning at $t=0.2 \mathrm{~s}$, lemon bility of the proposed strategy to react as tion conditions.

Fig. 12 shows the simulation results when $t$ ystem is perturbed by a type-II sag $\left(\delta=10^{\circ}\right)$. The mean value the injected active power is $300 \mathrm{~W}$ before the sag and $900 \mathrm{~W}$ after the sag due to the programed active power change. As it can be seen, the generated power never reaches $P_{\mathrm{Max}}$, thus, $P^{*}=P_{G}$ during the entire simulation. Under this condition, the inverter is able to provide some reactive power till the inverter maximum-rated current $I_{\text {Rated }}$ is reached. Note that the reactive power adapts its profile online to the changes produced in the generated power in order to safely maintain the inverter-rated current controlled at its maximum value.

Fig. 13 depicts the line-to-neutral voltage at phase $b$ and the corresponding current during the type-II sag. Observe that the $i_{\mathrm{b}}$ peak current change according to the delivered power. Before the sag, the peak current is low (approximately $1 \mathrm{~A}$ ). During the sag, After the sag, the peak current decrease up to approximately $4 \mathrm{~A}$ due to the increment in the active power. Note that the maximum

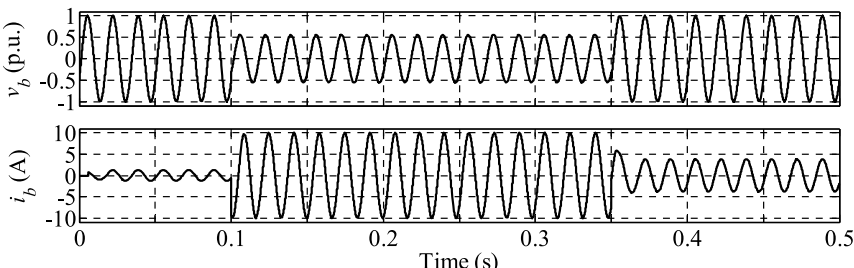

Fig. 13. Phase b voltage and current during the type II sag. Top: PCC line-toneutral voltage. Bottom: phase current.
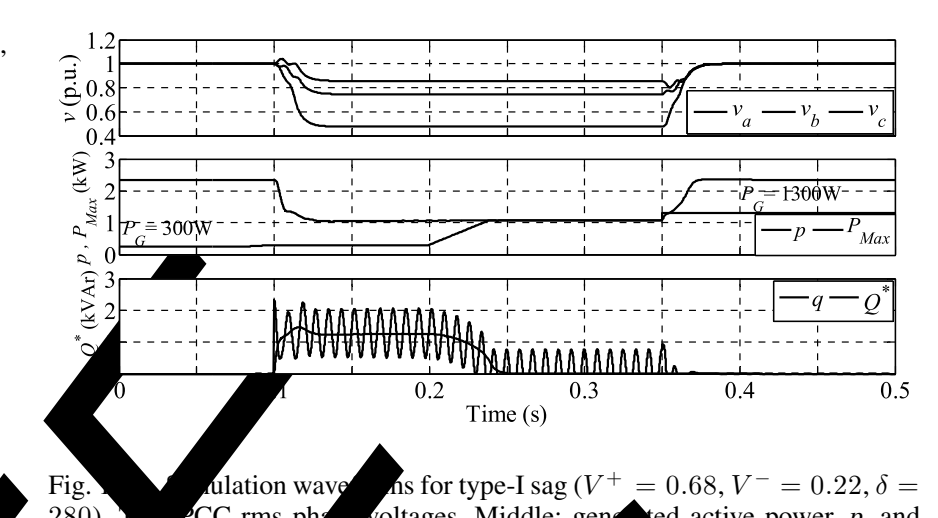
Fig.
280). CC rms ph poltages. Middle: gen ted active power, $p$, and
maximun
reactive pon (1)

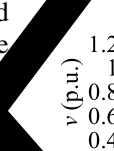

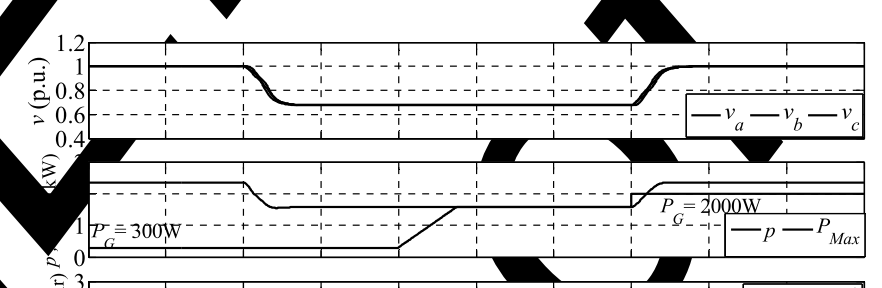
Table I has been simulated under three
terized by its positive- and negative-sequo sarac$V^{-}$, and the sequence phase angle $\delta[9]$, [3. it reaches $I_{\text {Rated }}$ because $v_{b}$ is the most dropped phase voltage. rated current is not surpassed at any time.

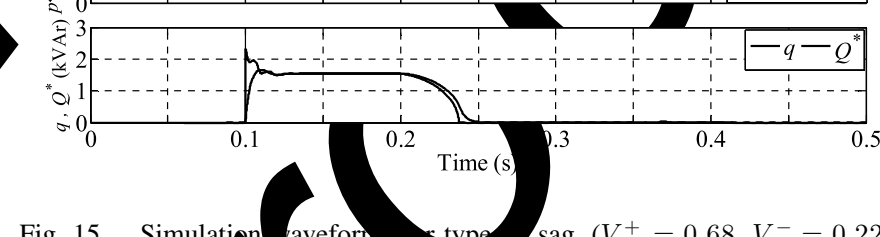

Fig. 15. Simulation avefor sag. $\left(V^{+}=0.68, V^{-}=0.22\right.$, $\delta=0$ ). Top: PCC hase volta adle: generated active power, $p$, and $\delta=0$ ). Top: PCC
maxir $P_{M}$ Bottom: measured reactive power, $q$, and reference rea Fig. 14 ws the simulations for the type I sag $\left(\delta=280^{\circ}\right) . \quad 510$ ctiy power change has been programmed from $300 \mathrm{~W} 511$ up $60 \mathrm{~W}$. In this test, the injection of the active power is 512 curtan by the controller approximately at $t=0.23 \mathrm{~s}$, once the 513 generate wer reaches $P_{\text {Max }}$. Thus, from this point till the 514 sag is clea $P^{*}=P_{\mathrm{Max}}$. After the sag, the delivered active 515 power increases up to $1300 \mathrm{~W}$. During this test, it is verified that 516 the inverter provides reactive power meanwhile the generated 517 power is below the limit $P_{\mathrm{Max}}$.

The well performance of the system during type-III sag is 519 similar to that obtained in previous tests, as shown in Fig. 15. 520 In this case, the change in the generated power has been pro- 521 grammed from $300 \mathrm{~W}$ up to $2000 \mathrm{~W}$. Thus, the system is able to 522 deliver this maximum value of the active power once the sag is 523 cleared. Since the voltage droop is balanced in the three phases, 524 

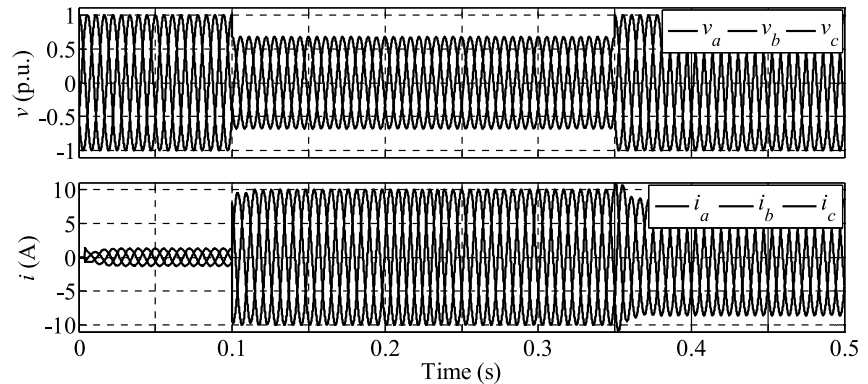

Fig. 16. Voltage and phase currents waveforms during the type-III sag. Top: PCC phase voltages. Bottom: phase currents.
TABLE III

COMPARISON With PREVIOUS STRATEGIES

\begin{tabular}{lccccc}
\hline \hline Strategy & $\begin{array}{c}\text { Deliver } \\
\text { to the } \\
\text { grid }\end{array}$ & $\begin{array}{c}\text { Peak } \\
\text { current } \\
\text { limita- } \\
\text { tion }\end{array}$ & $\begin{array}{c}\text { Injected } \\
\text { current } \\
\text { THD }\end{array}$ & $\begin{array}{c}\text { Reduce } \\
p \text { oscil- } \\
\text { lation }\end{array}$ & $\begin{array}{c}\text { Control } \\
\text { Com- } \\
\text { plexity }\end{array}$ \\
\hline$[11]$ & only P & No & High & No & Low \\
{$[12]$} & only Q & Yes & Low & No & Low \\
{$[13]$} & & Yes & Low & No & High \\
{$[15]$} & P and Q & Yes & Low & Yes & High \\
{$[16]$} & P and Q & Low \\
Proposal & P and Q & Yes & Low & Yes & \\
\hline \hline
\end{tabular}

TABLE II

PEAK CURRENT VALUES DURING DifFERENT SAGS

\begin{tabular}{lccc}
\hline \hline Sag type & I & II & III \\
\hline Sag & $V^{+}=0.68$ & $V^{+}=0.68$ & $V^{+}=0.68$ \\
Characteristics & $V^{-}=0.22$ & $V^{-}=0.22$ & $V^{-}=0$ \\
& $\delta=280$ & $\delta=10$ & $\delta=0$ \\
$i_{\mathrm{a}}(\mathrm{A})$ & 7.69 & 5.51 & 10.00 \\
$i_{\mathrm{b}}(\mathrm{A})$ & 6.01 & 10.00 & 10.00 \\
$i_{\mathrm{c}}(\mathrm{A})$ & 10.00 & 9.32 & 10.00 \\
\hline \hline
\end{tabular}

\section{E. Discussion on the Benefits of the}

The performance of VSI under voltage investigated. However, the best strategy is stl topic and depends on many aspects such as grt rated power type of prime mover, type of sag, ex al requirements, etc. The control strategy presented in this paper is based on a flexible reference current generator that can be adjusted by means of two control parameters to obtain different results in terms of power quality, balance among positive and negative sequences, active and reactive power injection characteristics, among others. In fact, it can reproduce previous injection strategies by proper selection of the control parameters.

One of the contributions of this paper is a particular selection of the control parameter which permits to preserve one remarkable feature of previous strategies such as the mitigation of active power oscillation. Furthermore, thanks to the proposed parameter selection, the referent current generator (see (12)(15)) turns into a simple and normalized structure that permits to develop two simple and compact expressions (see (29) and (31)). It is worth mentioning that these expressions incorporate the peak current limitation function and facilitate the devise of the proposed control strategy as shown in Fig. 2. The pro- posed strategy gives priority to the injection of active power 556 which matches correctly with the actual PV GCs requirements. 557 Furtherm , under sag situation, a reactive power reference is 558 online ofputed based on the remaining VSI current capacity. 559 This perty permits to support the grid during contingencies 560 and the same he, it protects the inverter against overcurrent. 561 ze propg shares important features with some previous 562 stra ies s as peak cy yent limitation and mitigation of active 563 powe ation. Fu ermore, it reduces the implementation 564 complex integrat these functionalit in two compact ex- 565 pressions. Idi a, the proposed strat pryvides outstand- 566 in ynamic fior that permits to obta looth transitions 567 der active power variations and also duri nges in the op- 568 cration mo (i.e., active power curtailment and ctive power 569 injection o summarize the discussio pares the 570 main ares of the proposal and $p$ fious s gies. 571 III voltage sag. By means the propos flexible current injection 575 strategy, two main obied es have be achieved. First, to safely 576 maintain the inject cun s contro d by the maximum rated 577 value independe $f$ the sa and generated power and, 578 secon lations in the injected active power. Both 579 obj ves ribut improve the grid stability and ensure an 580 nized us f the $m$ VSI power capability, improving the 581 ality of th jected po $\lambda$. The effectiveness of the proposed 582 ol str gy has been validated by a comprehensive set of 583 sin ti and experimental results. 584

\section{.}

1] F. Blaabj R. Teodorescu, M. Liserre, and A. V. Timbus, "Overview 586 of control and grid synchronization for distributed power generation sys- 587 tems," IEEE Trans. Ind. Electron., vol. 53, no. 5, pp. 1398-1409, Oct. 588 $2006 . \quad 2589$

[2] F. Blaabjerg, Z. Chen, and S. B. Kjaer, "Power electronics as efficient 590 interface in dispersed power generation systems," IEEE Trans. Power 591 Electron., vol. 19, no. 5, pp. 1184-1194, Sep. 2004. 592

[3] S. Martin-Martinez, E. Gomez-Lazaro, A. Molina-Garcia, A. Molina- 593 Garcia, A. Vigueras-Rodriguez, M. Milligan, and E. Muljadi, "Participa- 594 tion of wind power plants in the Spanish power system during events," in 595 Proc. IEEE Power Energy Soc. General Meeting, 2012, pp. 1-8. 596

[4] (2008 Oct.). Offprint of the Operation Procedure O.P. 12.2: Techni- 597 cal requirements for wind power and photovoltaic installations and any 598 
generating facilities whose technology does not consist on a synchronous generator directly connected to the grid, Asociación Empresarial Eólica. [Online]. Available: www.aeeolica.org

[5] M. Altin, O. Goksu, R. Teodorescu, P. Rodriguez, B.-B. Jensen, and L. Helle, "Overview of recent grid codes for wind power integration," in Proc. 12th Int. Conf. Optimization Electr. Electron. Equip., May 2010, pp. 1152-1160.

[6] Characteristics of the Utility Interface for Photovoltaic Systems, IEC Standard 61727, 2004

[7] S. Alepuz, S. Busquets-Monge, J. Bordonau, J. Martinez-Velasco, C. Silva, J. Pont, and J. Rodriguez, "Control strategies based on symmetrical components for grid-connected converters under voltage dips," IEEE Trans. Ind. Electron., vol. 56, no. 6, pp. 2162-2173, Jun. 2009.

[8] F. Wang, J. L. Duarte, and M. A. M. Hendrix, "Pliant active and reactive power control for grid-interactive converters under unbalanced voltage dips," IEEE Trans. Power Electron., vol. 26, no. 5, pp. 1511-1521, May 2011.

[9] A. Camacho, M. Castilla, J. Miret, J. C. Vasquez, and E. Alarcon-Gallo, "Flexible voltage support control for three phase distributed generation inverters under grid fault," IEEE Trans. Ind. Electron., vol. 60, no. 4, pp. 1429-1441, Apr. 2013.

10] J. Miret, A. Camacho, M. Castilla, L. García de Vicuña, and J. Matas, "Control scheme with voltage support capability for distributed generation inverters under-voltage sags," IEEE Trans. Power Electron., vol. 28, no. 11, pp. 5252-5262, Nov. 2013.

11] A. Camacho, M. Castilla, J. Miret, R. Guzman, and A. Borrell, "Reactive power control for distributed generation power plants to comply with voltage limits during grid faults," IEEE Trans. Power Electron., vol. 29 no. 11, pp. 2624-2634, Nov. 2014.

[12] J. Miret, M. Castilla, A. Camacho, L. García de Vicuña, and J. Mata "Control scheme for photovoltaic three-phase inverters to minimize currents during unbalanced grid-voltage sags," IEEE Trans. Powe tron., vol. 27, no. 10, pp. 4262-4271, Oct. 2012.

13] P. Rodriguez, A. Luna, J. Hermoso, I. Etxeberria-Otadui, R. and F. Blaabjerg, "Current control method for distributed gene generation plants under grid fault conditions" in Proc. IEEE nower Conf. Ind. Electron. Soc., Nov. 2011, pp. 1262-1269.

14] P. Rodriguez, G. Medeiros, A. Luna, M. Cavalcanti, "Safe current injection strategies for a STATCOM grid faults," in Proc. IEEE Energy Convers. Co pp. 3929-3935.

15] J. Suul, A. Luna, P. Rodriguez, and T. Un voltage-sensor-less power control for unbala Trans. Power Electron., vol. 27, no. 9, pp. 407

16] C.-T. Lee, C.-W. Hsu, and P.-T. Cheng, 'A lownique for grid-connected converters of Trans. Ind. Appl., vol. 47, no. 4, pp. 182

[17] A. Camacho, M. Castilla, J. Miret, A. Bor "Active and reactive power strategies with pe tributed generation inverters during unbalanced Ind. Electron., vol. 62, no. 3, pp. 1515-1525, Jul.

[18] M. Liserre, F. Blaabjerg, and S. Hansen, "Design an trol of an $L C L$ no. 5, pp. 1281-1291, Sep./Oct. 2005.

19] E. Figueres, G. Garcera, J. Sandia, F. Gonzalez-Espin, and J. C. Rubio, "Sensitivity study of the dynamics of three-phase photovoltaic inverters with an LCL grid filter," IEEE Trans. Ind. Electron., vol. 56, no. 3 pp. 706-717, Mar. 2009.

[20] A.K Abdelsalam, A. M. Massoud, S. Ahmed, and P. N. Enjeti, "High-performance adaptive perturb and observe MPPT technique for photovoltaic-based microgrids," IEEE Trans. Power Electron., vol. 26, no. 4, pp. 1010-1021, Apr. 2011.

[21] M. Mohseni, S. M. Islam, and M. A. S. Masoum, "Impacts of voltage sags on DFIG-based wind turbines considering phase-angle jump, voltage recovery, and sag parameters," IEEE Trans. Power Electron., vol. 26, no. 5, pp. 1587-1598, May 2011.

[22] M. H. J. Bollen, "Algorithms for characterizing measured three-phase unbalanced voltage dips," IEEE Trans. Power Del., vol. 18, no. 3, pp. 937-944, Jul. 2003.

[23] V. Ignatova, P. Granjon, and S. Bacha, "Space vector method for voltage dips and swells analysis," IEEE Trans. Power Del., vol. 24, no. 4, pp. 2054-2061, Oct. 2009.

[24] A. Yazdani, and R. Iravani, Voltage-Sourced Converters in Power Systems. Hoboken, NJ, USA: Wiley, 2010.
[25] H. Akagi, Y. Kanazawa, and A. Nabae, "Instantaneous reactive power 673 compensator comprising switching devices without energy storage com- 674 ponents," IEEE Trans. Ind. Appl., vol. IA-20, no. 3, pp. 625-630, May 675 1984.

[26] P. Rodriguez, A. V. Timbus, R. Teodorescu, M. Liserre, and F. Blaabjerg, 677 "Flexible active power control of distributed power generation systems 678 during grid faults," IEEE Trans. Ind. Electron., vol. 54, no. 5, pp. 2583- 679 2592, Oct. 2007

[27] R. Tonkoski, L. A. C. Lopes, and T. H. M. El-Fouly, "Coordinated active 681 power curtailment of grid connected PV inverters for overvoltage preven- 682 tion," IEEE Trans. Sustainable Energy, vol. 2, no. 2, pp. 139-147, Apr. 683 2011 .

[28] J. F. Conroy and R. Watson, "Low-voltage ride-through of a full con- 685 verter wind turbine with permanent magnet generator," IET Renew. Power 686 Gener, vol. 1, no. 3, pp. 182-189, Sep. 2007.

[29] J. Matas, M. Castilla, J. Miret, L. García de Vicuña, and R. Guzman, "An 688 adaptive pre-filtering method to improve the speed/accuracy trade-off of 689 voltage sequence detection methods under adverse grid conditions," IEEE 690 Trans. Ind. Electron., vol. 61, no. 5, pp. 2139-2151, May 2014.

[30] F. Rodriguez, E. Bueno, M. Aredes, L. Rolim, F. Neves, and M. Cavalcanti, 692 "Discrete-time implementation of second order generalized integrators for 693 grid c nverters," in Proc. IEEE 34th Annu. Conf. Ind. Electron., Nov. 2008， 694 $\begin{array}{ll}\text { pp. } & 694 \\ \text {-181. } & 695\end{array}$

[31] D Zmood, D. G. Holmes, and G. H. Bode, "Frequency-domain analysis 696 hree-phase linear current regulators," IEEE Trans. Ind. Appl., vol. 37, 697 O. 2, pp. 60 10, Mar./Apr. 2001. 698 V. Ignatoy Granjon, and S. Bacha, "Space vector method for volt- 699 age dips swells analysis," IEEE Trans. Power Del., vol. 24, no. 4, 700
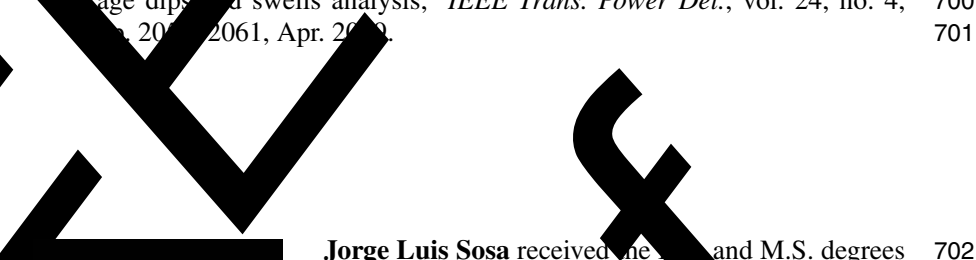

Jorge Luis Sosa receivedne and M.S. degrees 702 in electrical engineering from thy versidad de Los 703 Andes, Mérida, Ven in 1993 1997, respec- 704 tively, and the $\mathrm{Pb}$ aregry $m$ mical Uni- 705 versity of Catal a, Barcelo, Spain, L $2007 . \quad 706$ Since 1999, has been a Pro sor with the Scien- 707 $\begin{array}{lll}\text { tific Instrument n Laboratory niversidad de los } 708 \\ \text { Andes, Mérida, } \\ \text { zuela, whe teaches courses } & 709\end{array}$ $\begin{array}{lll}\text { Andes, Mérida, } & \text { zuela, whe he teaches courses } & 709 \\ \text { in electranics. His } & \end{array}$ 711 712 713 714

power electronics. po systems interruptible power systems, and

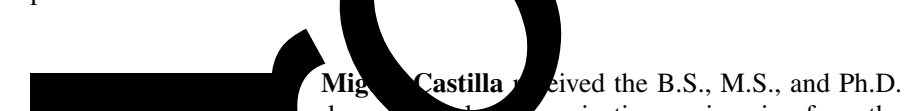
degree. Technical umversity of Catalonia, Barcelona, Spain, in 1988, 1995, and 1998, respectively.

Since 2002, he has been an Associate Professor in 719 - Tepartment of Electronic Engineering, Technical 720 Un ity of Catalonia, where he teaches courses on 721 analog circuits and power electronics. His research 722 interests are in the areas of power electronics, non- 723 linear control, and renewable energy systems. $\quad 724$ 724
725

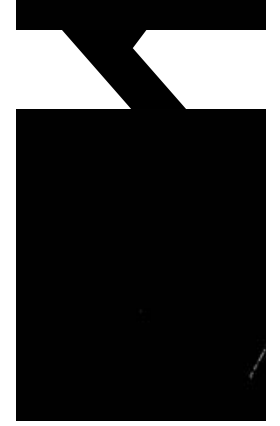

Jaume Miret (M'98) received the B.S. degree in 726 telecommunications, the M.S. degree in electronics, 727 and the Ph.D. degree in electronics from the Univer- 728 sitat Politecnica de Catalunya, Barcelona, Spain, in 729 1992, 1999, and 2005, respectively. 730

From 1993 to 2011, he was an Assistant Professor 731 in the Department of Electronic Engineering, Univer- 732 sitat Politecnica de Catalunya, Spain, where he has 733 been an Associate Professor since 2011 and teaches 734 courses on digital design and circuit theory. His re- 735 power filters, and digital control. search interests include dc-to-ac converters, active 736 


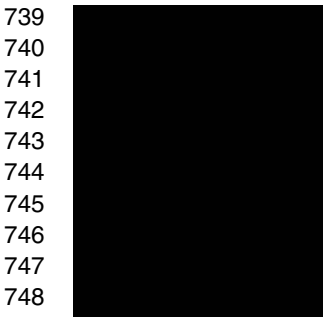

José Matas received the B.S., M.S., and Ph.D. degrees in telecommunications engineering from the Technical University of Catalonia, Barcelona, Spain, in 1988, 1996, and 2003, respectively.

From 1988 to 1990, he was an Engineer in a consumer electronics company. Since 1990, he has been an Associate Professor in the Department of Electronic Engineering, Technical University of Catalonia, Barcelona, Spain. His research interests include power-factor-correction circuits, active power filters, uninterruptible power systems, distributed power sys-

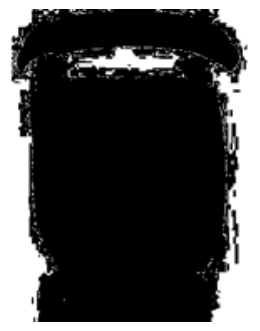

Y. A. Al-Turki received the Ph.D. degree in power 752 systems from the University of Manchester, Manch- 753 ester, U.K., in 1985.

Since 1999, he has been a Professor with the De- 755 partment of Electrical and Computer Engineering, 756 King Abdulaziz University, Jeddah, Saudi Arabia, 757 where he is currently the Dean of Research. His 758 current research interests include system modeling, 759 power system dynamics, renewable energy, and mi- 760 crogrids.

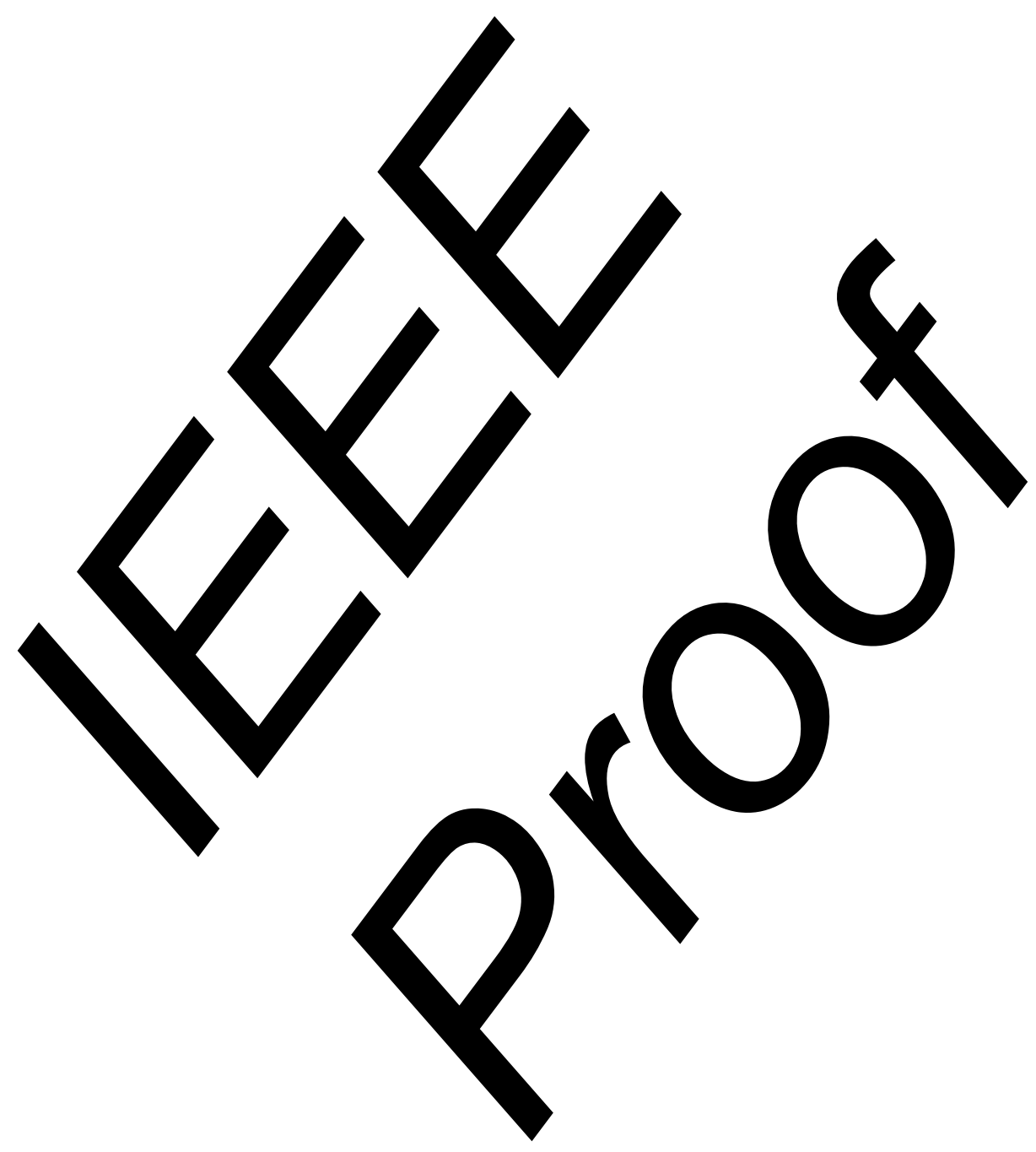

